\title{
В. ТИЙТ
}

\section{КОМПАКТНЫЙ ВАКУУМНЫЙ МОНОХРОМАТОР}

V. TIIT. KOMPAKTNE VAAKUMMONOKROMAATOR

V. TIIT, COMPACT VACUUM MONOCHROMATOR

\author{
(Представил Г. Лийдья)
}

\begin{abstract}
Для спектроскопических исследований, проводимых в вакуумной ультрафиолетовой области спектра 50-400 нм, нами создан монохроматор нормального падення. Благодаря компактной конструкции он может быть относительно легко присоединен к разным экспериментальным установкам.
\end{abstract}

\section{Оптическая схема и основные элементы конструкции монохроматора}

Используемая нами оптическая схема описана в $\left.{ }^{1}\right]$ (общий вид монохроматора ТМС-04 представлен на рис. 1). В нашем случае угол между падающим и дифрагированным лучами составляет $20^{\circ}$, расстояния в меридиональной плоскости от входной щели до вершины решетки и от последней до выходной щели составляют соответственно 600 и 420 мм. Сканирование спектра осуществляется поворотом неклассической решетки вокруг неподвижной оси, параллельной штрихам решетки, и проходящей через ее вершину при неподвижных щелях (см. рис. 2).

Применяемая нами решетка рассчитана А. В. Савушкиным. Ее радиус кривизны 0,5 м, количество штрихов $\sim 1200$ в 1 мм, заштрихованное поле $50 \times 40 \mathrm{~m} \mathrm{~m}^{2}$.

Монохроматор состоит из двух основных частей. Спектральную часть составляют две трубы из нержавеющей стали ( $\varnothing 120$ мм), сваренные в единый узел. Эта часть является несущей конструкцией для узла дифракционной решетки, редуктора, диафрагм, вакуумных затворов и щелей. Перед. щелями находятся управляемые снаружи через сильфоны фильтры для исключения наложения порядков в спектре. Перемещение щелей вдоль оптической оси для юстировки осуществляется снаружи без нарушения вакуума. Щели раскрываются от 0,001 до 0,4 мм. Затворы имеют прозрачные окна из кварца. Сканирование спектра осуществляется поворотом дифракционной решетки с помощью рычага через сильфон с использованием шагового двигателя. Спектральная часть может в упорах поворачиваться до $90^{\circ}$ вокруг входящей оптической оси. Она может быть отделена от основания и присоедена к другой испытательной установке.

Основание монохроматора служит для размещения всей вакуумной системы, крепления электрических соединений и ручек управления. Оно имеет четыре колеса, которые позволяют легко перемещать установку. В рабочем положении монохроматор целесообразно закрепить на упоры, которые располагаются у колес. В транспортном положении форвакуумный насос крепится четырьмя болтами к основанию. В рабочем положении с целью уменьшения вибрации болты следует вывинчивать и опускать насос на пол. 


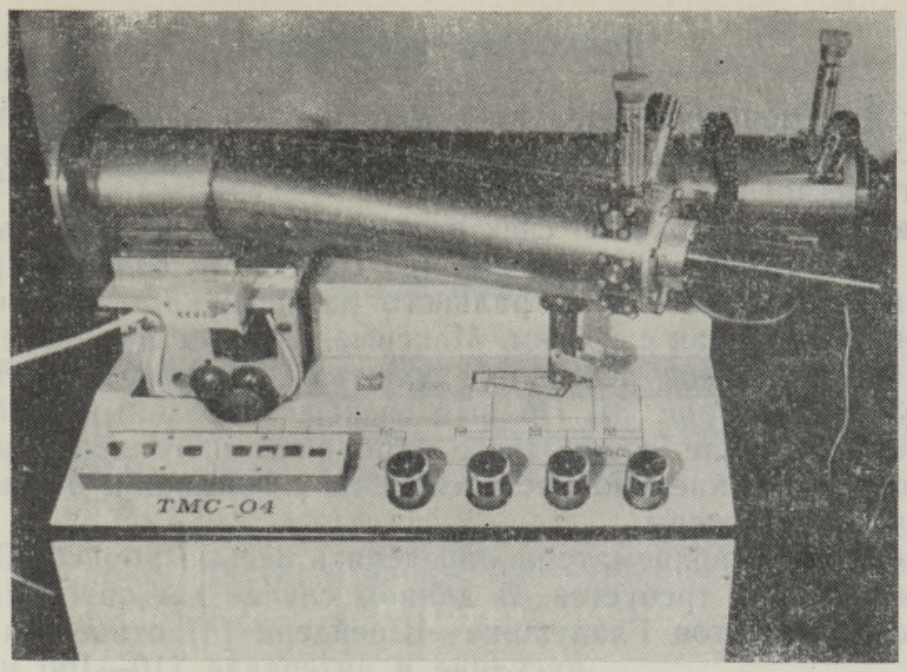

Рис. 1. Вакуумный монохроматор ТМС-04.

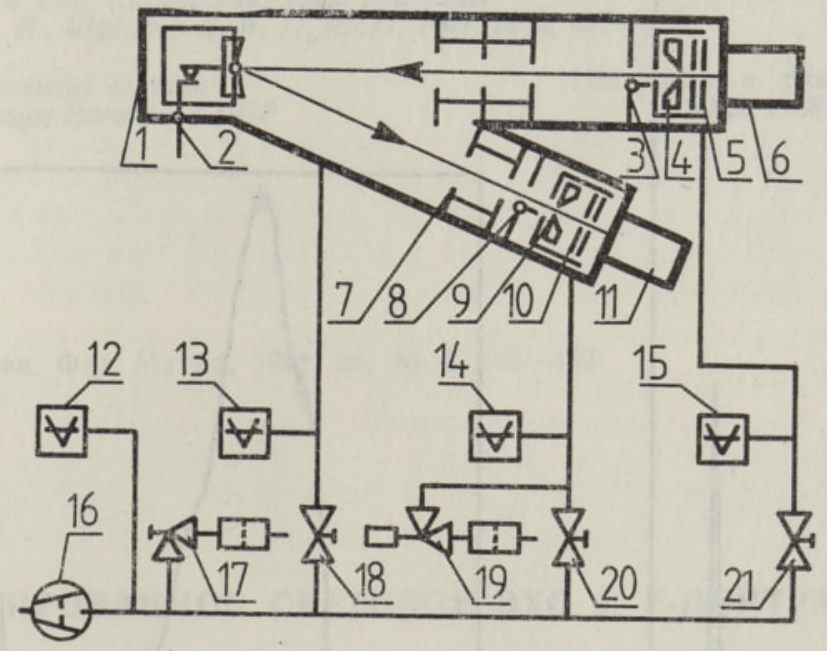

Рис. 2. Оптическая схема, разрез спектральной части и схема вакуумной системы. 1 - корпус, 2 - узел дифракционной решетки вместе с синусным механизмом, 3 - затвор секции источника излучения, 4 - узел входной щели, 5 - заслонки и фильтры, 6 - источник излучения, 7 - диафрагмы, 8 - затвор секции приемника излучения, 9 - узел выходной щели, 10 - заслонки и фильтры, 11 - приемник излучения, $12-15-$ датчики вакуума, $16-$ форвакуумный насос, $17-21-$ вакуумные краны.

Вакуумная система монохроматора позволяет проводить как одновременную, так и раздельную откачку форвакуумным насосом объема дифракционной решетки, секции источника излучения и секции приемника излучения. Если этого недостаточно, то возможно присоединить к торцу вакуумной камеры у дифракционной решетки дополнительный высоковакуумный насос. При необходимости можно через фильтры пустить воздух в секцию приемника или в форвакуумный насос. Разрежение определяется четырьмя датчиками вакуума как у насоса, так и в трех вышеупомянутых секциях, которые могут быть включены последовательно. 


\section{Результаты испытаний}

Испытания монохроматора показали, что его основные узлы работают вполне удовлетворительно и спектральные характеристики соответствуют рассчитанным.

Кинетически возможный спектральный диапазон охватывает область от нулевого порядка до 410 нм. При этом, однако, приходится примириться с падением спектрального разрешения в длинноволновой части спектра, начиная с 250 нм. Максимальное спектральное разрешение при использовании решетки с золотым покрытием составляет не менее 0,03 нм (см. рис. 3). Полный спектр, записанный со скоростью 85 нм/мин, в случае водородного источника излучения показан на рис. 4. Вследствие инерционности системы регистрации острые пики в спектре слегка сглажены.

Пропускание монохроматора определить весьма трудно. Во многих случаях этого и не требуется. В данном случае мы определили с помощью коэффициентов Гладущака-Шрейдера $\left[{ }^{2}\right]$ относительное пропускание в интервале $110-160$ нм. Эксперимент показал, что пропускание монохроматора при длине волны 110 нм на $20 \%$ ниже, чем при 160 нм.

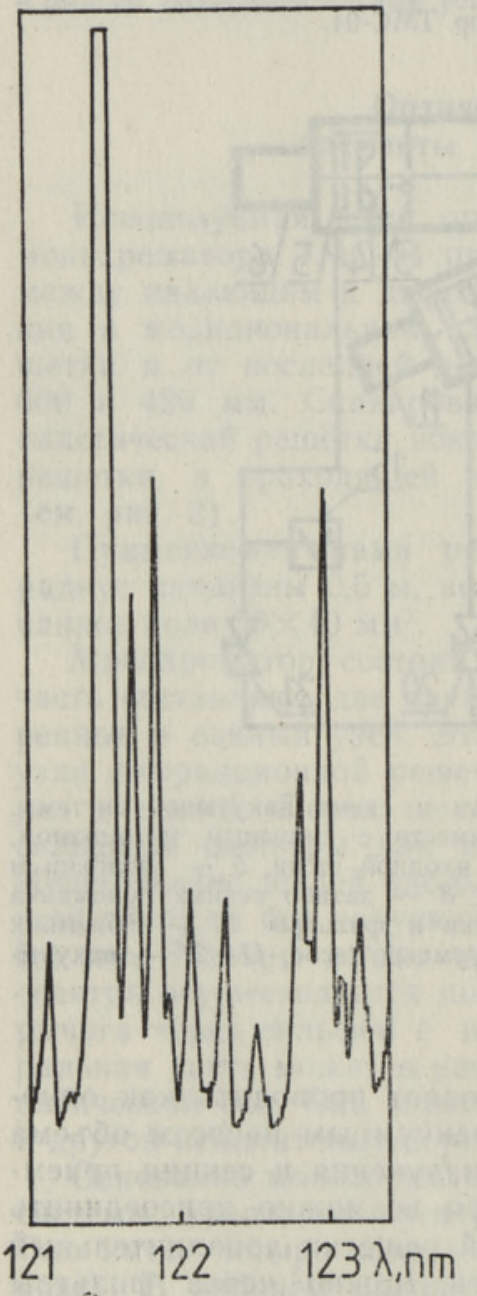

Рнс. 3. Участок спектра разрядной водородной лампы около $L_{\alpha}$ Щели по 3 мкм.

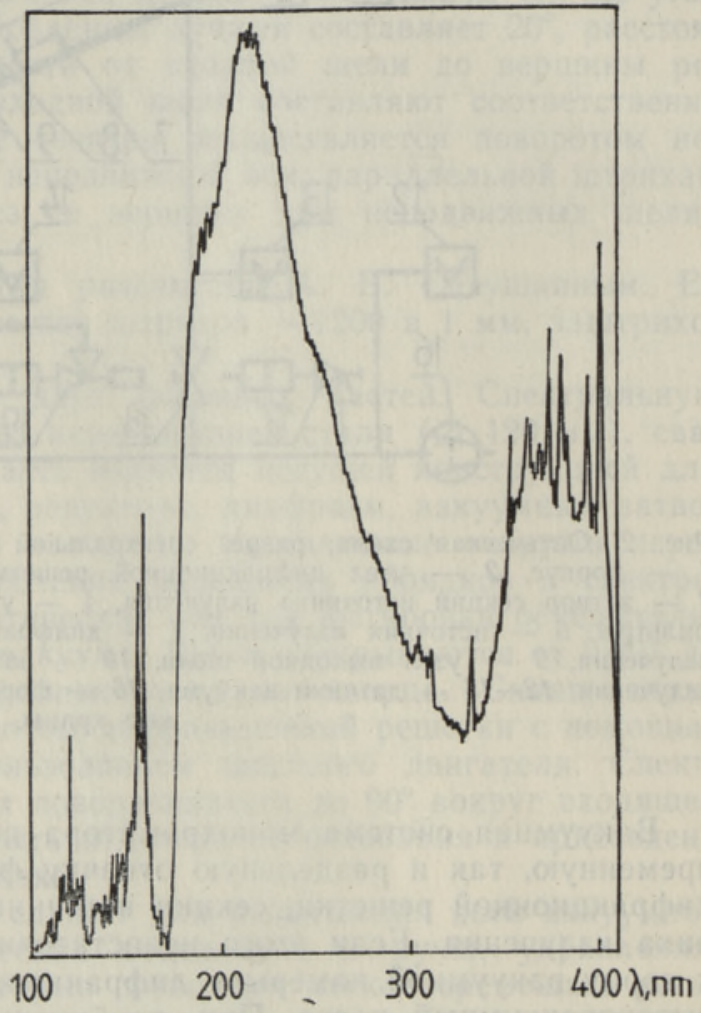

Рис. 4. Спектр разрядной водородной лампы. Около 173 нм отключен кварцевый фильтр и уменьшена чувствительность регистрирующей системы в 50 раз. Щели по 20 мкм. 
Реальные свойства поверхности дифракционной решетки и отражение излучения от элементов конструкции в монохроматоре создают определенный фон рассеянного излучения. Мы оценили, что при использовании водородной лампы доля рассеянного излучения при длине волны 160,8 нм составляет около $10^{-3}$.

\title{
Заключение
}

Применение неклассической дифракционной решетки позволяет создать вакуумный монохроматор весьма компактной конструкции для широкого спектрального диапазона, который с успехом может применяться для решения многих задач спектроскопии.

Автор глубоко благодарен П. Паасмяе, А. Вахт, Х. Локко, Р. Рянкел и Н. Герулис за участие в работе при создании монохроматора.

\section{ЛИТЕРАТ У РА}

1. Старцев Г. П., Савуикин А. В., Тверитинов М. П. // Сб. докладов II советскофранцузского симпозиума по оптическому приборостроению (Москва, 1618 марта 1981 г.). Москва, 1982, 222-229.

2. Гладущак В. Н., Шрейдер Е. Я. // ЖПС, 1967, № 6, 437-440.

\author{
Ннститут физики \\ Академии наук Эстонской ССР \\ Поступила в редакцию \\ 23/XII 1988
}

Изв. АН Эстонии. Физ. Матем., 1989, 38, № 4, 449-452

\section{удК 535.33}

\section{M. РЯТСЕП}

\section{СТИМУЛИРОВАННОЕ СВЕТОВОЕ ЭХО В F-ЦЕНТРАХ КВr}

M. RATSEP. STIMULEERITUD FOOTONKAJA KBr-KRISTALLI F-TSENTRITEL

M. RATSEP. STIMULATED PHOTON ECHO OBSERVED ON F-CENTRES IN KBr

\section{(Представил П. Саари)}

1. Стимулированное светове эхо (СЭ) проявляется в эксперименте как запаздывающий во времени оптический отклик на возбуждение системы примесных атомов или молекул последовательно тремя световыми импульсами $\left[{ }^{1,2}\right]$. Механизм возникновения СЭ можно представить как результат модуляции спектра третьего импульса за счет его взаимодействия со спектральной решеткой, наведенной в неоднородно уширенной полосе поглощения совместным когерентным действием первых двух возбуждающих импульсов. Согласно преобразованию Фурье отмеченная модуляция спектра и проявляется во временной зависимости прошедшего сигнала (точнее, затухания свободной поляризации) в виде импульса СЭ. Если возбуждающие импульсы действуют в моменты времени $t_{1}=0, t_{2}>0, t_{3}>t_{2}$, то СЭ наблюдается как четвертый импульс в момент времени $t_{4}=t_{2}+t_{3}$. СЭ - когерентное явление, интенсивность которого зависит от процессов фазовой релаксации, 